\title{
Giant Incisional Hernia: Which Treatment? Case Report and Review of Literature
}

\author{
Danilo Coco $^{1 *}$, Silvana Leanza ${ }^{2}$ \\ ${ }^{1}$ Department of General Surgery, Ospedali Riuniti Marche Nord, Pesaro, Italy; ${ }^{2}$ Department of General Surgery, Carlo Urbani \\ Hospital, Jesi (Ancona), Italy
}

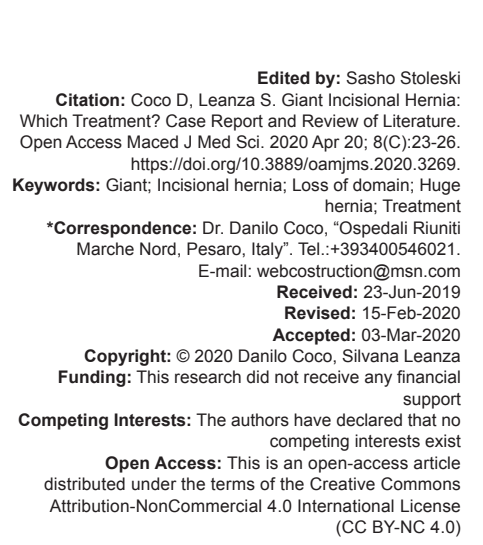

Introduction

Incisional hernias are one of the most common complications after abdominal surgery especially in patient with high-risk factors for developing an incisional hernia as old age, vascular disease, diabetes, obesity, renal failure, hepatic disease, protein deficiency, immunosuppression, and smoking [1]. Incisional hernias develop in 3.8-11.5\% after abdominal surgery [2]. "Loss of domain" (LOD) is defined when the ratio of the volume of the hernia sac to the volume of the abdominal cavity is $>0.5$ [3]. It is necessary to measure the volume through the sagittal and axial reconstruction of the computed tomography (CT) scan, $50 \%$ according to the literature. The management of giant incisional hernia $(\mathrm{GIH})$ with loss of abdominal domain remains a surgical challenge with high recurrence rate of $30 \%$, elevated comorbidity and a mortality rate between $0 \%$ and $5 \%$. Patients with complex hernia repairs experiencing post-operative failure have a higher mortality rate [4]. We present a case of 70-year-old Caucasian woman with many comorbidities, questioning if it is right to perform or not operation.

\section{Case Report}

A 70-year-old woman presented at our emergency room with a $24 \mathrm{~h}$ history of abdominal bloating. She reported no vomiting. Her medical history included arterial hypertension, diabetes mellitus, and obesity due to body mass index $35 \mathrm{~kg} / \mathrm{m}^{2}$. She had a previous surgical history of an open umbilical hernia repair without the use of prosthetic mesh a year ago. She had a Glasgow Coma Scale of 15 . Her vital signs showed hypertension with arterial blood pressure of $180 / 100 \mathrm{mmHg}$, not tachycardia and not fever. Routine blood investigations not showed leukocytosis, normal hemoglobin, and protein chain reaction in the range. Arterial blood gas was normal. On physical examination, she presented with a surgical scar in the middle abdomen, abdominal bulge, and $\mathrm{GIH}$. Incisional hernia showed expansile impulse on coughing, no tenderness, it had a uniform consistency, mobile, there were no pulsations. It contained large and small intestine, partially reducible. The defect was about $10 \mathrm{~cm}$ in diameter and there were no complications. No signs of peritoneal irritation. Abdominal TC scan demonstrated a GIH about $10 \times 11 \mathrm{~cm}$, associated with colon and ileus with "LOD," not distended ileus with thickening of the intestinal 
wall and air-fluid levels (Figures 1-4). The patient refused operation, but we made a multidisciplinary meeting to discuss how to treat other future cases like this.

\section{Discussion}

Approximately 200,000 incisional hernia repairs are performed each year in the United

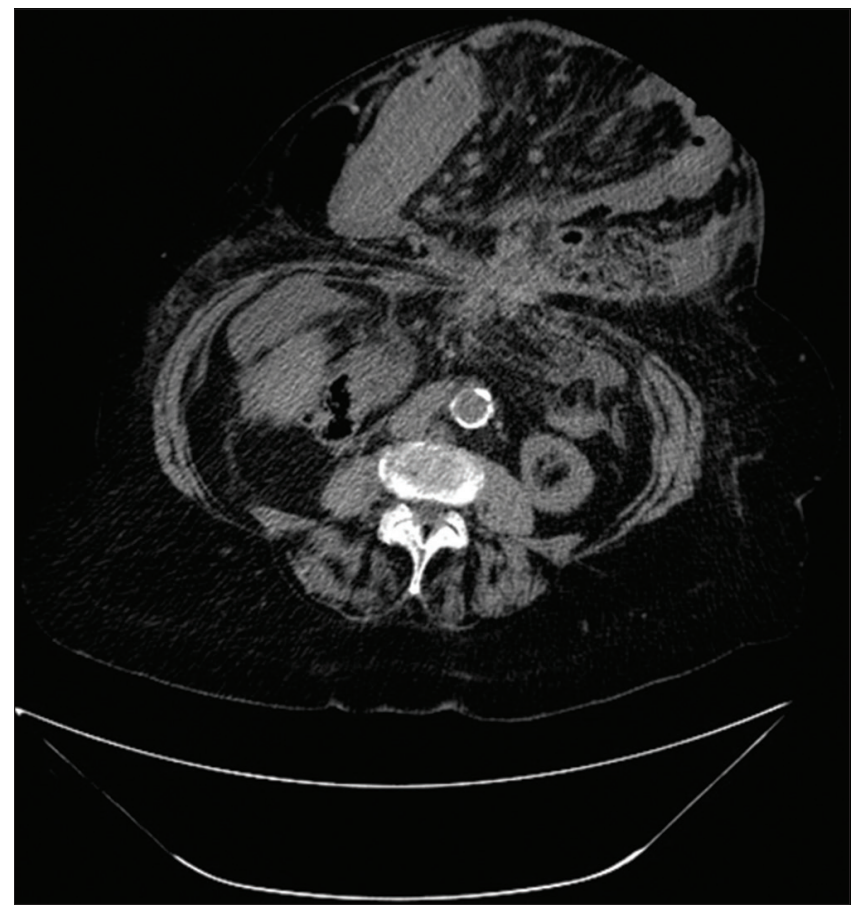

Figure 1: Giant incisional hernia

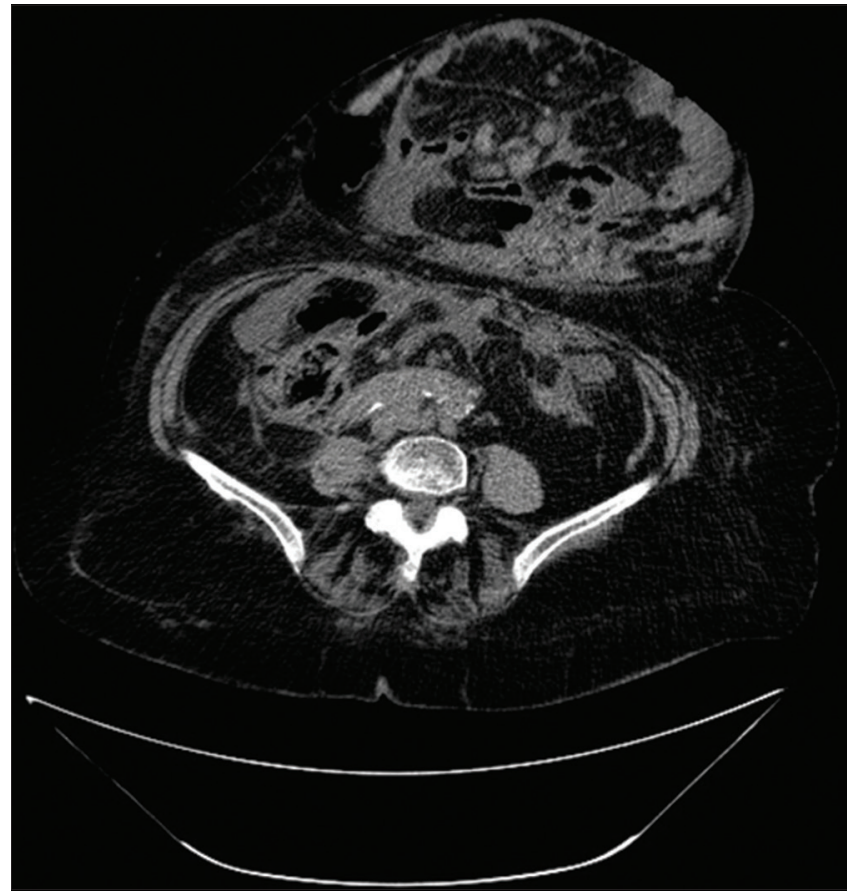

Figure 2: Air-fluid levels
States alone at a financial cost of nearly 2.5 billion dollars [5]. High-risk factors for developing incisional hernia are old age, vascular disease, diabetes, obesity, renal failure, hepatic disease, protein deficiency, immunosuppression, smoking, not correct technical closure, and wound infection [6]. In literature, incidence of giant hernia occurs $11-23 \%$ [7]. Of these, $11 \%$ of patients have a defect $>15 \mathrm{~cm}$ [8]. The overall morbidity rate was a median $32 \%$, mortality rate of $0-5 \%$, and recurrence rate from $10 \%$ to $50 \%$ [9]. "Loss of abdominal domain" occurs when the intra-abdominal contents can no longer stay within the abdominal cavity [10]. Giant

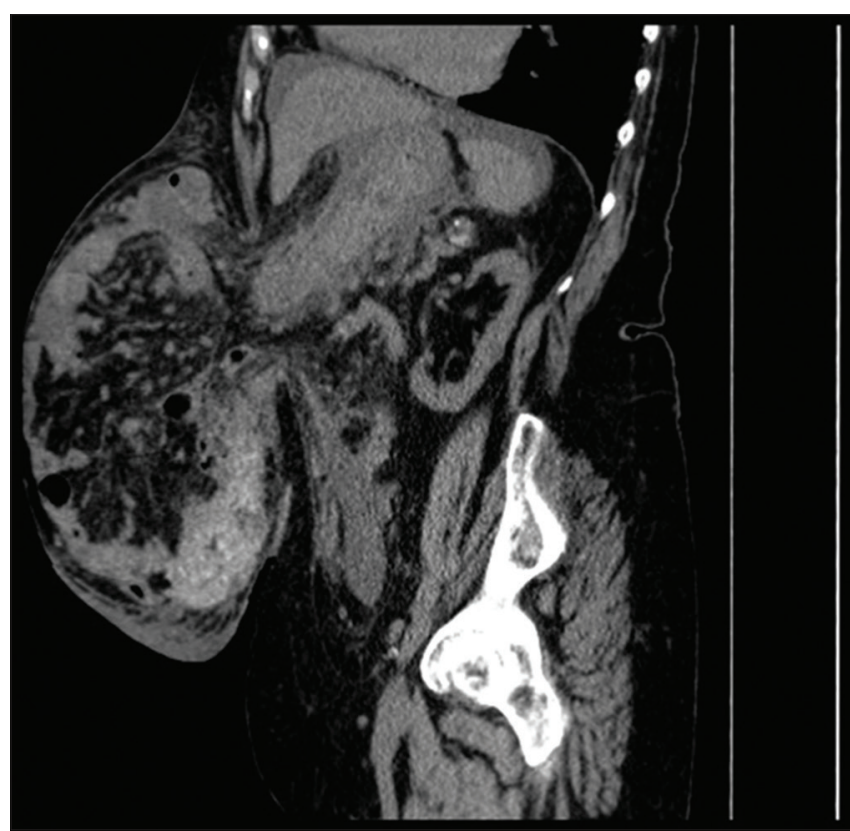

Figure 3: "Loss of domain"

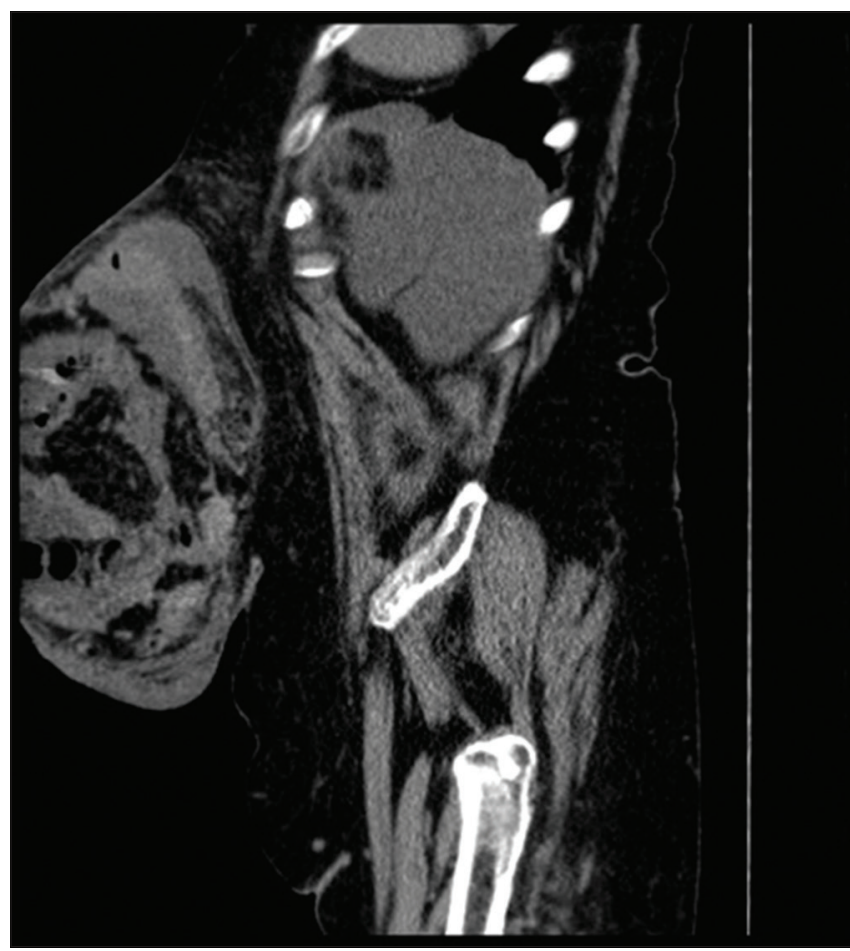

Figure 4: Not distended ileus with thickening of intestinal wall 
ventral hernias are considered in cases where the hernia orifice is $>10 \mathrm{~cm}$ [11]. Surgical repair for $\mathrm{GIH}$ is a high-risk surgical procedure with more liable to complications [12]. First, reduction of the contents is difficult [13]. Second, the risk of recurrence is high [14]. Finally, the residual skin needs excision for cosmetic reasons [15]. There are many options to repair huge hernia such as pneumoperitoneum, abdominal flap, component separation, bowel resection, or mesh use [16]. Every technique has very high post-operative complications such as elevated abdominal pressure, contamination, infections, seromas, hematomas, hemorrhage, cardiovascular disease, pulmonary insufficiency, pulmonary embolism, fistulas, and mortality. Carbonell et al. recommend percutaneous vena cava filter, anti-thrombotic medication, placement of insufflation catheter, liquid diet with protein, incentive spirometry, daily cure of skin, pneumoperitoneum insufflation monitoring vital signs, repeated CT scan after 7 days of insufflation to decide the suitability of the abdominal repair, or continue pneumoperitoneum for other 4-5 days. Component separation technique with sublay mesh appeared to be better with lower morbidity and lower recurrence rates compared with other methods. Surgical technique is not standard but is a taylored procedure. Surgical treatment should be centralized to discuss every case with a multidisciplinary team (general surgeon, plastic surgeon, and radiologist) [17], [18], [19], [20]. Welldesigned randomized trials are seriously warranted. We present this case to ask to riders what they do in abdominal loss of domain.

\section{Conclusion}

Loss of abdominal domain occurs when the intra-abdominal contents can no longer lie within the abdominal cavity [10]. Giant ventral hernias are considered in cases where the hernia orifice is $>10 \mathrm{~cm}$. Surgical repair for Giant Incisional Hernia $(\mathrm{GIH})$ is a high risk surgical procedure with more liable to complications.

\section{References}

1. Sanders DL, Kingsnorth AN. The modern management of incisional hernias. BMJ. 2012;344:e2843. https://doi. org/10.1136/bmj.e2843 PMid:22573647

2. Mäkelä JT, Kiviniemi H, Juvonen T, Laitinen S. Factors influencing wound dehiscence after midline laparotomy. Am J Surg. 1995;170(4):387-90. https://doi.org/10.1016/ s0002-9610(99)80309-2

\section{PMid:7573734}

3. Rutkow IM. Demographic and socioeconomic aspects of hernia repair in the United States in 2003. Surg Clin North Am. 2003;83(5):1045-51, 5-6. https://doi.org/10.1016/ s0039-6109(03)00132-4

PMid: 14533902

4. Bucknall TE, Cox PJ, Ellis H. Burst abdomen and incisional hernia: A prospective study of 1129 major laparotomies. Br Med J (Clin Res Ed). 1982;284(6320):931-3. https://doi.org/10.1136/ bmj.284.6320.931

PMid:6279229

5. Dubay DA, Wang X, Kuhn MA, Robson MC, Franz MG. The prevention of incisional hernia formation using a delayed-release polymer of basic fibroblast growth factor. Ann Surg. 2004;240(1):179-86. https://doi.org/10.1097/01. sla.0000131576.12153.ab

PMid:15213634

6. Read RC, Yoder G. Recent trends in the management of incisional herniation. Arch Surg. 1989;124(4):485-8. https://doi. org/10.1001/archsurg.1989.01410040095022

PMid:2649047

7. Luijendijk RW, Hop WC, van den Tol MP, de Lange DC, Braaksma MM, IJzermans JN, et al. A comparison of suture repair with mesh repair for incisional hernia. N Engl J Med. 2000;343(6):392-8. https://doi.org/10.1056/nejm200008103430603

PMid:10933738

8. Carlson MA. Acute wound failure. Wound healing. Surg Clin North Am. 2001;77(3):607-35.

9. National Health Statistics Center. Detailed Diagnose and Procedures. National hospital Discharge Survey. Vol. 12. Hyattsville, Maryland: National Health Statistics Center; 1995.

10. Wedbush Morgan securities: Biotechnology in wound care. 2001;4:1-82.

11. Franz MG, Kuhn MA, Nguyen K. Early biomechanical wound failure: A mechanism for ventral incisional hernia formation. Wound Rep Reg. 2001;9:140-1.

12. Pollock AV, Evans M. Early prediction of late incisional hernias. Br J Surg. 1989;76(9):953-4. https://doi.org/10.1002/ bjs. 1800760926 PMid:2804595

13. Viidik A, Gottrup F. Mechanics of healing soft tissue wounds. In: Schonbein GS, Woo S, Zweifach B, editors. Frontiers in Biomechanics. New York: Springer; 1986. p. 263-79. https://doi. org/10.1007/978-1-4612-4866-8_19

14. Memona AA, Khanb A, Zafarc H, Murtazac G, Zaidi M. Repair of large and giant incisional hernia with onlay mesh: Perspective of a tertiary care hospital of a developing country. Int J Surg. 2013;11(1):41-5. https://doi.org/10.1016/j.ijsu.2012.11.006 PMid:23178155

15. Anthony $\mathrm{T}$, Bergen $\mathrm{PC}$, Kim LT, Henderson M, Fahey $\mathrm{T}$, Rege RV, et al. Factors affecting recurrence following incisional herniorrhaphy. World J Surg. 2000;24(1):95-100. https://doi. org/10.1007/s002689910018 PMid:10594211

16. DuBay DA, Franz MG. The biology of acute wound healing failure. Surg Clin North Am. 2003;83(3):463-81

17. Franz MG, Kuhn MA, Wright TE, Wachtel TL, Robson MC. Use of the wound healing trajectory as an outcome determinant for acute wound healing. Wound Repair Regen. 2000;8(6):511-6. https://doi.org/10.1046/j.1524-475x.2000.00511.x PMid:11208178

18. Carbonell AM. In: Jones DB, editor. Massive Ventral Hernia with Losso of Domain. 8th ed. New York: Lippincott Williams and Wilkins; 2013. p. 367-72. 
19. Deligiannidis N, Papavasiliou I, Sapalidis K, Kesisoglou I, Papavramidis S, Gamvros O. The use of three different mesh materials in the treatment of abdominal wall defects. Hernia. 2002;6(2):51-5. https://doi.org/10.1007/s10029-002-0054-4

PMid: 12152638
20. van't Riet M, de Vos van Steenwijk PJ, Bonthuis F, Marquet RL, Steyerberg EW, Jeekel J, et al. Prevention of adhesion to prosthetic mesh: Comparison of different barriers using an incisional hernia model. Ann Surg. 2003;237(1):123-8. https:// doi.org/10.1097/00000658-200301000-00017 